\title{
A therapeutic barium enema is a practical option to control bleeding from the appendix
}

\author{
Youkou Konno ${ }^{1}$, Mikihiro Fujiya ${ }^{2 *}$, Kazuyuki Tanaka ${ }^{1}$, Aki Sakatani ${ }^{1}$, Mizue Shimoda', Akihiro Hayashi ${ }^{1}$, Momotaro Muto', \\ Mitutaka Inoue ${ }^{1}$, Jun Sakamoto ${ }^{3}$, Kensuke Oikawa ${ }^{4}$, Nobuhiro Ueno ${ }^{2}$, Yuhei Inaba ${ }^{2}$, Kentaro Moriichi ${ }^{2}$ and Yutaka Kohgo ${ }^{2}$
}

\begin{abstract}
Background: Acute lower gastrointestinal hemorrhage originating from the appendix is rare and often intractable, because it is almost impossible to approach the bleeding point by endoscopy. We herein describe the first case of bleeding from the appendix, which was successively controlled by a therapeutic barium enema administered into the appendix.

Case presentation: A 71-year-old male visited our hospital because of melena. He has been receiving an anti-coagulation drug, ticlopidine hydrochloride, for 10 years. By an emergency colonoscopy, a hemorrhage was detected in the appendix, and the lesion responsible for the bleeding was regarded to exist in the appendix. Two hundred milliliters of $50 \mathrm{~W} / \%$ barium was sprayed into the orifice of the appendix using a spraying tube. The bleeding could thus be immediately stopped, and a radiological examination revealed the accumulation of barium at the cecum and the orifice of the appendix. The barium accumulation disappeared by the next day, and no obvious anal bleeding was observed. Two weeks after stopping the bleeding from the appendix, an appendectomy was performed to prevent any further refractory hemorrhaging. The patient has had no complaints of any abdominal symptoms or anal bleeding for 10 months.
\end{abstract}

Conclusions: A therapeutic barium enema is a useful procedure to control bleeding from the appendix and to avoid emergency surgery, such as partial cecectomy and hemicolectomy.

Keywords: Appendix bleeding, Barium enema, Intestinal hemorrhage, Appendicitis

\section{Background}

Acute lower gastrointestinal hemorrhage originating from the appendix is rare and often intractable [1-22], because it is very difficult to approach the bleeding point in the appendix by endoscopy. Therefore, in most cases with bleeding from the appendix, an emergency operation was necessary [1-13,15-22]. We herein report the first case of the bleeding associated with the appendix ulcer which was successively controlled by the administration of a therapeutic barium enema into the appendix.

\section{Case presentation}

A 71-year-old male visited our hospital because of melena. He was suffering from diabetes mellitus and the sequelae

\footnotetext{
* Correspondence: fjym@asahikawa-med.ac.jp

${ }^{2}$ Division of Gastroenterology and Hematology/Oncology, Department of Medicine, Asahikawa Medical University, 2-1 Midorigaoka-higashi, Asahikawa, Hokkaido 078-8510, Japan

Full list of author information is available at the end of the article
}

of a cerebral infarction. He has been receiving oral diabetic drugs and an anti-coagulation drug, ticlopidine hydrochloride for 10 years. His blood pressure was $150 / 83 \mathrm{mmHg}$ and the pulse rate was $105 /$ minute. A blood examination revealed a high level of blood sugar at $162 \mathrm{mg} / \mathrm{dL}$, and hemoglobin A1c of $6.6 \%$, but neither a decrease in red blood cells nor hemoglobin. A computed tomography scan in the abdomen detected a high density fluid of ascites, but no inflammatory changes in any organs, including the intestinal tract. By an emergency colonoscopy, the fresh blood in the entire colon, but not in the ileum, and the blood and coagula in the orifice of the appendix were observed (Figure 1A). After washing the orifice with water, a hemorrhage was detected in the appendix (Figure 1B), and the lesion responsible for bleeding was regarded to exist in the appendix. After obtaining the patient's informed consent, $200 \mathrm{ml}$ of $50 \mathrm{~W} / \mathrm{V} \%$ barium was sprayed into the orifice of the appendix using a spraying tube

\section{Biomed Central}




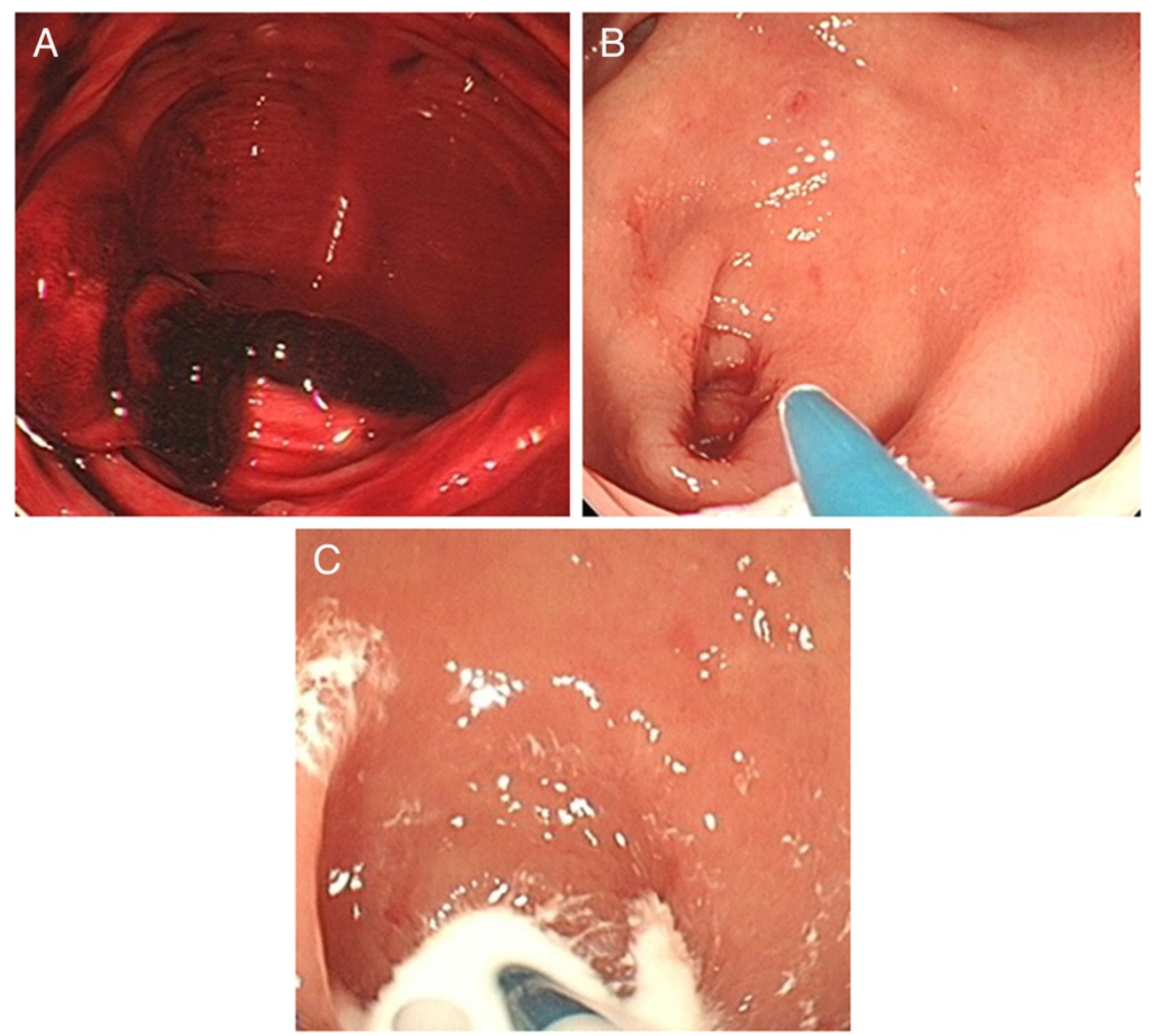

Figure 1 The findings of emergency endoscopy. Blood and coagula were observed in the cecum (A). After washing with water, a hemorrhage from the appendix was detected (B). Two hundred $\mathrm{ml}$ of $50 \mathrm{~W} / \mathrm{N} \%$ barium was sprayed into the orifice of the appendix through a spraying tube (C).

(Figure 1C), because a therapeutic barium enema has been shown to be a useful procedure to control bleeding from a diverticulum $[23,24]$. The bleeding could be immediately stopped, and a radiological examination revealed the accumulation of barium at the cecum and the orifice of the appendix (Figure 2A). The barium accumulation disappeared by the next day (Figure 2B) and no obvious anal bleeding was observed in the patient. Two weeks after stopping the bleeding from the appendix, an appendectomy was performed to prevent further refractory hemorrhage from the appendix. A gross specimen showed ulceration, but no tumorous lesions, at the tip of the appendix (Figure 3A). A severe infiltration of neutrophils and lymphocytes within a shallow ulcer was histologically observed (Figure 3B). The administration of the anti-coagulant ticlopidine hydrochloride, was restarted two weeks after the operation. The patient has had no complaints of any abdominal symptoms, including anal bleeding, for 10 months.

\section{Discussion and conclusion}

This report presented the first case of bleeding from an appendix ulcer that was successfully controlled with therapeutic barium enema. To date, 23 cases of bleeding from the appendix have been reported [1-22] (Table 1). The age of the patients with bleeding from the appendix ranged from 9 to 76 years of age. Sixteen patients were male, while the others were female. The causes of the bleeding included diverticulitis [1], Crohn's disease $[2,4,16]$, a mucinous cyst [6], aorta-appendix fistula [15], ectopic uterus mucosa [10], angiodysplasia [11,14], intussusceptions $[3,8,9,13]$, gastrointestinal stromal tumor [20] and intestinal tuberculosis [21]. Anti-coagulation drugs were administered in 4 cases $[5,17,20]$. In the present case, the administration of the anti-coagulation drug, ticlopidine hydrochloride, was thought to aggravate the bleeding from the appendix, while the cause of the ulceration itself of the appendix remains unclear. The therapeutic barium enema is thought to have stopped the acute bleeding from the appendix, and the suspension of the administration of the anti-coagulant helped to prevent re-bleeding. In many of the reported cases, the appendix bleeding has been diagnosed via colonoscopy.

Up to now, an emergency operation, including partial cecectomy and hemicolectomy, is generally conducted to control the bleeding in most cases, but no non-operative 

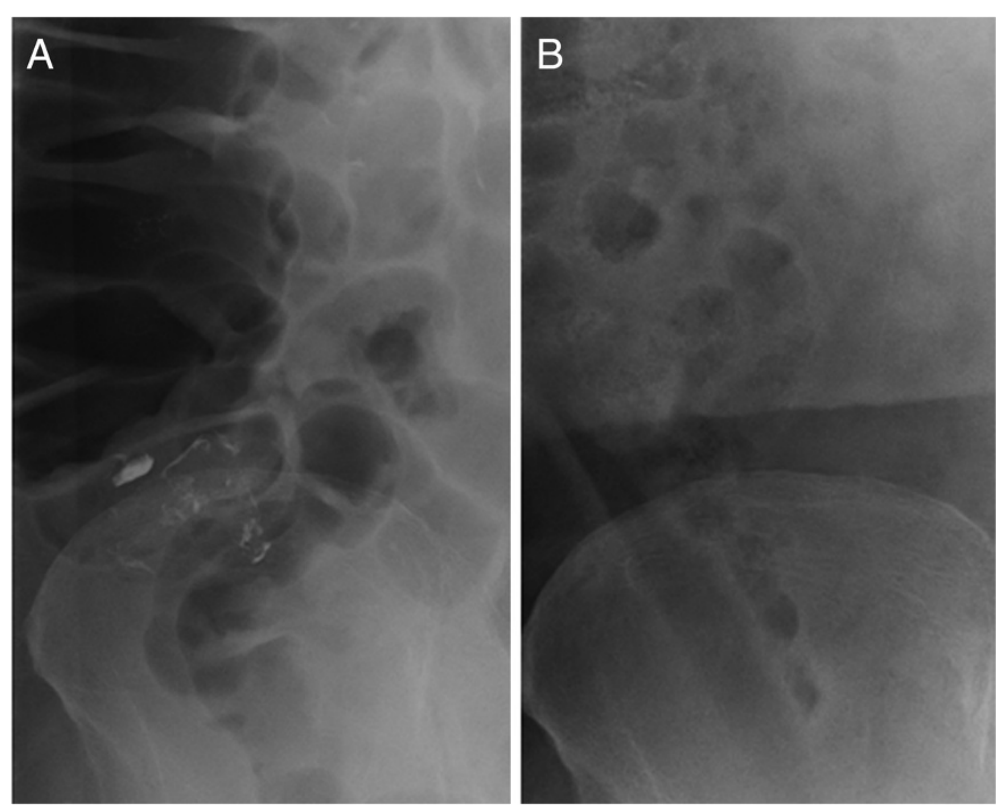

Figure 2 Radiological examinations of the abdomen. A radiological examination showed the accumulation of the barium at the cecum and orifice of the appendix (A). By the next day, the accumulation had almost completely disappeared (B).

therapeutic strategy for bleeding from the appendix has yet been established. Only one case of the embolization of the responsible artery has so far been reported [14]. As the therapeutic use of a barium enema has recently been shown to be a useful procedure to treat diverticular bleeding $[23,24]$, we thought that the use of a therapeutic barium enema could also be a practical and less invasive option for controlling such intractable appendix bleeding. In fact, the present case is the first reported case in which a therapeutic barium enema successfully controlled such bleeding.

The mechanism underlying this effect was speculated to be protection of the intestinal epithelia, compression of the blood vessels, coagulating action and the production
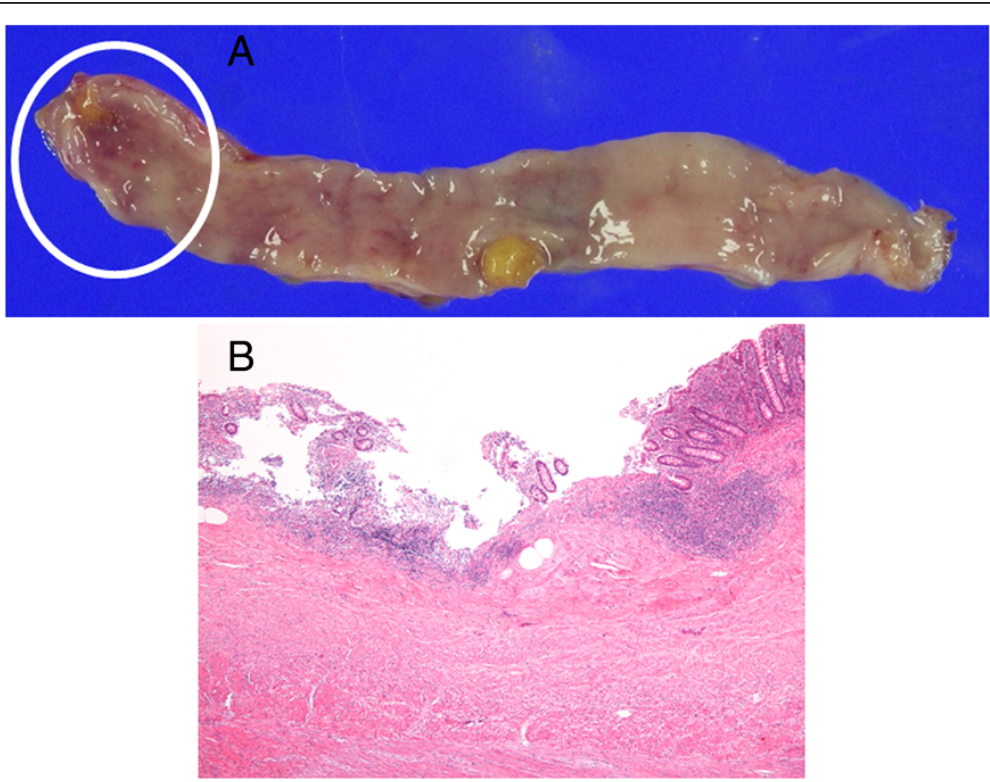

Figure 3 Histological features of the surgical specimen. A gross surgical specimen showed an ulcer in the tip of the appendix with no tumorous lesion (A). The histological sections revealed a severe infiltration of neutrophils and lymphocytes within a shallow ulcer (Hematoxilin eosin staining, $\times 40)(B)$. 
Table 1 The reported cases and our case of bleeding from appendix

\begin{tabular}{|c|c|c|c|c|c|c|}
\hline Authors & Age & Sex & $\begin{array}{l}\text { Administration of } \\
\text { anti-coagulation drugs }\end{array}$ & $\begin{array}{l}\text { Method of } \\
\text { diagnosis }\end{array}$ & Treatment & $\begin{array}{l}\text { Histopathologic } \\
\text { findings }\end{array}$ \\
\hline Tamvakopoulos (1969) [1] & 40 & M & & Not described & Conventional appendectomy & Diverticulitis \\
\hline Tamvakopoulos (1969) [1] & 43 & $\mathrm{~F}$ & & Barium enema & Conventional appendectomy & Diverticulitis \\
\hline Geerken and Gibbons (1974) [2] & 17 & M & & Barium enema & Conventional appendectomy & Crohn's disease \\
\hline Brewer and Wangensteen (1974) [3] & 24 & $\mathrm{~F}$ & & Barium enema & Ileocecal resection & Intussusception \\
\hline Brown and Peter (1976) [4] & 19 & M & & Barium enema & Right hemicolectomy & Crohn's disease \\
\hline Milewski (1977) [5] & 14 & M & $\begin{array}{l}\text { Aspirin tablet taken on } \\
\text { the night of admission }\end{array}$ & Not described & Ileocecal resection & Appendicitis, abscess \\
\hline Mullen (1979) [6] & 63 & M & & Barium enema & Right hemicolectomy & Diverticulum, mucocele \\
\hline Norman et al (1980) [7] & 48 & M & & Angiography & $\begin{array}{l}\text { Conventional } \\
\text { appendectomy }\end{array}$ & Diverticulum \\
\hline Mclntosh et al (1990) [8] & 18 & $\mathrm{~F}$ & & $C F, C T$ & $\begin{array}{l}\text { Conventional } \\
\text { appendectomy }\end{array}$ & Intussusception \\
\hline Jevon et al (1992) [9] & 32 & $\mathrm{~F}$ & & CF & Partial cecectomy & Intussusception \\
\hline Shome et al (1995) [10] & 33 & $\mathrm{~F}$ & & CF & Ileocecal resection & Endometriosis \\
\hline So et al (1995) [11] & 42 & M & & CF & $\begin{array}{l}\text { Laparoscopic } \\
\text { appendectomy }\end{array}$ & Angiodysplasia \\
\hline Morales et al (1997) [12] & 60 & M & & CF & Laparoscopic appendectomy & Appendicitis \\
\hline Gupta et al (2000) [13] & 9 & M & & CF & Partial cecectomy & Intussusception \\
\hline Kyokane et al (2001) [14] & 76 & $\mathrm{~F}$ & & Angiography & $\begin{array}{l}\text { Transcatheter arterial } \\
\text { embolization, conventional } \\
\text { appendectomy }\end{array}$ & Angiodysplasia \\
\hline Monaghan and Cogbill (2002) [15] & 66 & M & & US, CT & $\begin{array}{l}\text { Conventional } \\
\text { appendectomy, AAAresection }\end{array}$ & $\begin{array}{l}\text { Primary aortoappendiceal } \\
\text { fistula, appendicitis }\end{array}$ \\
\hline Lima et al (2004) [16] & 16 & M & Aspirin 200mg/day & CF & Conventional appendectomy & Crohn's disease \\
\hline Rivera-Irigoin et al (2005) [17] & 51 & M & & CF & Conventional appendectomy & Aspirin-induced ulcer \\
\hline Yamazaki et al (2006) [18] & 53 & $\mathrm{~F}$ & & $C F, C T$ & Laparoscopic appendectomy & Appendicitis \\
\hline Ogi et al (2006) [19] & 44 & M & & CF & Laparoscopic appendectomy & Hematoma \\
\hline Kim et al (2007) [20] & 56 & M & Few tablets of NSAID & CF & Right hemicolectomy & GIST \\
\hline Kuntanapreeda (2008) [21] & 20 & M & & CF & $\begin{array}{l}\text { Conventional appendectomy, } \\
\text { partial cecectomy }\end{array}$ & Tuberculosis \\
\hline Baek (2010) [22] & 42 & M & & $C T, C F$ & Laparoscopic appendectomy & Mucosal erosion \\
\hline Our case & 71 & M & Ticlopidine hydrochloride & $C T, C F$ & $\begin{array}{l}\text { Therapeutic barium enema, } \\
\text { laparoscopic appendectomy }\end{array}$ & Ulcer \\
\hline
\end{tabular}

of a thrombus by the barium itself. In the current case, such functions of the barium enema appeared to be effective for controlling the bleeding from the appendix. From this perspective, the therapeutic barium enema is thought to be useful for the treatment of appendiceal bleeding caused by erosions or ulcers in the appendix, as well as that caused by other disorders, such as diverticulitis and angiodysplasia. We were apprehensive that the therapeutic barium enema might cause the obstruction of the appendix, leading to severe appendicitis. However, the accumulation of barium was almost completely eliminated by the next day, and an appendectomy was successfully performed. An appendectomy is a routine laparoscopic procedure that poses much less risk and less invasive for the patient than an emergency operation, such as cecectomy and hemicolectomy, and arterial embolization. Therefore, the use of a therapeutic barium enema is thought to be a practical and safe procedure to control bleeding from the appendix and to avoid an emergency operation.

\section{Consent}

The patient has given their consent for the case report to be published. Written informed consent was obtained from the patient for publication of this case report and any accompanying images. A copy of the written consent is available for review by the Editor-in-Chief of this journal. 


\section{Competing interest}

Tha authors declare that they have no competing interests.

\section{Authors' contributions}

The work presented here was carried out in collaboration between all authors. All authors have contributed to, seen and approved the manuscript.

\section{Author details}

'Department of Internal Medicine, Engaru-Kosei general Hospital, Engaru, Hokkaido 099-0404, Japan. Division of Gastroenterology and Hematology/ Oncology, Department of Medicine, Asahikawa Medical University, 2-1 Midorigaoka-higashi, Asahikawa, Hokkaido 078-8510, Japan. ${ }^{3}$ Department of Gastroenterology, Sapporo Higashi Tokushukai Hospital, Sapporo, Hokkaido 065-0033, Japan. ${ }^{4}$ Department of pathology, Asahikawa-Kosei general Hospital, Asahikawa, Hokkaidō 078-8211, Japan.

Received: 18 June 2012 Accepted: 17 October 2013

Published: 25 October 2013

\section{References}

1. Tamvakopoulos SK: Clinical observation on diverticulosis-diverticulitis of the appendix rectal bleeding in association with symptoms of acute appendicitis suggests diagnosis. R I Med J 1969, 52:443-444.

2. Geerken RG, Gibons RB: Isolated Crohn's disease of the appendix: case report. Mil Med 1974, 139:215-217.

3. Brewer RJ, Wangensteen SL: Appendiceal intussusception: an unusual cause of painless rectal bleeding. Am Surg 1974, 40:319-320.

4. Brown WK, Peters RW: Crohn's Disease of the appendix presenting as lower intestinal hemorrhage and cecal mass. Am J Gastroenterol 1976, 65:349-352.

5. Milewski PJ: Appendix abscess with intestinal haemorrhage. $\mathrm{Br}$ Med J 1977, 1:147.

6. Mullen JT: Mucocele of the appendix associated with hematochezia. South Med J 1979, 72:766-767.

7. Normann DA, Morisson EB, Meyers WM Jr: Massive gastrointestinal hemorrhage from a diverticulum of the appendix. Dig Dis Sci 1980, 25:145-147

8. McIntosh JC, Mroczek EC, Baldwin C, et al: Intussusception of the appendix in a patient with cystic fibrosis. J Pediatr Gastroenterol Nutr 1990, 11:542-544.

9. Jevon GP, Daya D, Qizilbash AH: Intussusception of the appendix a report of four cases and review of the literature. Arch Pathol Lab Med 1992, 116:960-964.

10. Shome GP, Nagaraju M, Munis A, et al: Appendicecal endometoriosis presenting as massive lower intestinal hemorrhage. Am J Gastroenterol 1995, 90:1881-1883.

11. So JB, Alexander DJ, Chong AP, et al: Laparoscopic appendectomy in the management of the acute lower gastrointestinal bleeding. Gastrointest Endosc 1995, 42:488-489.

12. Morales TG, Yalam J, Dinning JP, et al: Acute lower gastrointestinal bleeding from the appendix. Gastrointest Endosc 1997, 46:458-460.

13. Gupta P, Chwals W, Guandalini S: Intussusception of the appendix: another poorly recognized cause of rectal bleeding. J Pediatr Gastroenterol Nutr 2000, 30:320-323.

14. Kyokane $T$, Akita $Y$, Katayama M, et al: Angiodysplasia of the appendix. Am J Gastroenterol 2001, 96:242-243.

15. Monaghan $\mathrm{K}$, Cogbill TH: Primary aortoappendiceal fistula: case report and review of the literature. J Vasc Surg 2002, 35:1284-1286.

16. Lima SE Jr, Speranzini MB, Guiro MP: Isolated Crohn's disease of the appendix as a source of enterorrhagia. Arq Gastroenterol 2004, 41:60-63.

17. Rivera-lrigoín R, De Sola-Earle C, Palma-Carazo F, et al: Active lower gastrointestinal bleeding due to appendiceal ulcer. Gastroenterol Hepatol 2005, 28:445-446.

18. Yamazaki K, Nakao K, Tsunoda A, et al: Successful laparoscopic treatment of hemorrhage from the appendix with phlegmonous acute appendicitis: a case report and review of the literature. Gastrointest Endosc 2006, 63:877-880

19. Ogi M, Kawamura KJ, Konishi F, et al: Idiopathic hemorrhage from appendix. Jichi Medical University Journal 2006, 29:217-221.
20. Kim KJ, Moon W, Park Ml, et al: Gastrointestinal stromal tumor of appendix incidentally diagnosed by appendiceal hemorrhage. World I Gastroenterol 2007, 13:3265-3267.

21. Kuntanapreeda K: Tuberculous appendicitis presenting with lower gastrointestinal hemorrhage- a case report and review of the literature. J Med Assoc Thai 2008, 91:937-942.

22. Baek SK, Kim YH, Kim SP: Acute lower gastrointestinal bleeding due to appendiceal mucosal erosion. Surg Laparosc Endosc Percutan Tech 2010, 20:110-113.

23. Chorost MI, Fruchter G, Kantor AM, et al: The therapeutic barium enema revisited. Clin Radiol 2001, 56:856-858.

24. Iwamoto J, Mizokami Y, Shimokobe K, et al: Therapeutic barium enema for bleeding colonic diverticula: four case series and review of the literature. World J Gastroenterol 2008, 14:6413-6417.

doi:10.1186/1471-230X-13-152

Cite this article as: Konno et al:: A therapeutic barium enema is a practical option to control bleeding from the appendix. BMC Gastroenterology 2013 13:152.

\section{Submit your next manuscript to BioMed Central and take full advantage of:}

- Convenient online submission

- Thorough peer review

- No space constraints or color figure charges

- Immediate publication on acceptance

- Inclusion in PubMed, CAS, Scopus and Google Scholar

- Research which is freely available for redistribution 